08

\title{
Механические свойства полимерных композитов с наночастицами диоксида кремния
}

\author{
(C) О.А. Москалюк, ${ }^{2}$ А.М. Самсонов, ${ }^{1}$ И.В. Семенова, ${ }^{1}$ ॠ В.Е. Смирнова, ${ }^{2}$ В.Е. Юдин ${ }^{2}$ \\ ${ }^{1}$ Физико-технический институт им. А.Ф. Иофрфе РАН, \\ 194021 Санкт-Петербург, Россия \\ ${ }^{2}$ Институт высокомолекулярных соединений РАН, \\ 199004 Санкт-Петербург, Россия \\ T e-mail: irina.semenova@mail.ioffe.ru
}

(Поступило в Редакцию 29 июня 2016 г.)

По расплавной технологии получены образцы нанокомпозитов на основе полиметилметакрилата и полистирола с добавлением наночастиц диоксида кремния, поверхностно модифицированных силазанами. Исследовано влияние этих наночастиц на вязкоупругие свойства нанокомпозитов с помощью динамического механического анализа и показано, что введение 20 mass.\% $\mathrm{SiO}_{2}$ приводит к повышению в среднем на $30 \%$ модуля упругости нанокомпозитов при изгибе.

DOI: 10.21883/JTF.2017.02.44136.1963

\section{Введение}

Полимерные нанокомпозитные материалы (ПНК) находят в настоящее время все более широкое применение в таких областях как авиа- и автомобилестроение, где подвергаются разнообразным динамическим нагрузкам. При этом если для измерения статических механических параметров материалов разработаны стандартные процедуры измерений (ISO, ANSI и т.д.), то общепринятых методов измерения динамических модулей упругости пока не существует. Помимо того что значения модулей упругости сильно зависят от способа получения полимера, метода измерений, часто эти характеристики измеряются с большими погрешностями. В особенности это касается модулей упругости третьего порядка, ошибка измерения которых может составлять десятки и даже сотни процентов.

Как известно, многие аморфные полимеры, такие, например, как полистирол (ПС), полиметилметакрилат (ПММА), поликарбонат (ПК) в стеклообразном состоянии обладают выраженными нелинейно упругими свойствами. Можно предположить, что нанокомпозиты на их основе также будут демонстрировать нелинейно упругие свойства, но при этом иметь отличные от матрицы физико-механические параметры. Знание нелинейно упругих свойств этих полимеров имеет большое значение, в частности, для формирования в них объемных уединенных волн (солитонов) деформации [1]. Нами ранее было показано (см. [1,2] и приведенные там ссылки), что возможность формирования в материале нелинейной уединенной волны определяется комбинацией упругих модулей второго и третьего порядков материала, геометрическими параметрами волновода и характеристиками возбуждающего импульса (ударной волны). Таким образом, информация об упругих характеристиках материала имеет решающее значение при определении возможности формирования в нем солитона деформации. Отметим, что солитоны деформации могут переносить упругую энергию на большие расстояния почти без потерь [2,3], и возможность их генерации в различных конструкциях в процессе эксплуатации, в особенности в таких жизненно важных областях, как авиакосмическая техника, или транспортировка нефти и газа, необходимо принимать во внимание.

Технология получения ПНК нацелена на создание материалов, в которых путем направленного сочетания компонентов (полимерной матрицы и наполнителей различной природы) достигаются заранее заданные свойства. Такой способ получения ПНК дает возможность создавать принципиально новые и разнообразные конструкции, способствующие увеличению прочности, снижению массы, улучшению физических свойств изделий [4-7].

Как известно, создание эффективных ПНК на основе термопластов возможно с использованием различных методов, из которых наиболее перспективным является экструзионный метод введения наночастиц в объем полимера через его расплав. Одним из основных достоинств этого метода по сравнению с растворной технологией и полимеризацией in situ является отсутствие многостадийности процесса и растворителей [8-10].

Важными факторами, определяющими физико-механические свойства ПНК, являются адгезионное взаимодействие наполнителя и связующего, а также равномерное диспергирование наполнителя в объеме полимерной матрицы. Такое взаимодействие твердых наночастиц с полимером может быть достигнуто различными путями, из которых наибольшее значение имеет поверхностная химическая модификация наполнителя [11-13].

Целью настоящей работы является создание по расплавной технологии образцов полимерных нанокомпозитов на основе ПММА и ПС, наполненных модифицированными наночастицами диоксида кремния, а также исследование влияния наполнителя на термомеханические свойства полученных материалов с помощью динамического механического анализа. 
Таблица 1. Характеристики диоксида кремния марки Aerosil R812

\begin{tabular}{l|c}
\hline \multicolumn{1}{c|}{ Параметр } & Значение \\
\hline Удельная площадь поверхности, $\mathrm{m}^{2} / \mathrm{g}$ & $260 \pm 30$ \\
Размер частиц, nm & $\sim 7$ \\
Содержание углерода, mass.\% & $2.0-3.0$ \\
Содержание диоксида кремния, mass.\% & $\geq 99.8$ \\
Содержание окиси железа, mass.\% & $\leq 0.01$ \\
Содержание окиси алюминия, mass.\% & $\leq 0.05$ \\
pН & $5.5-7.5$ \\
Насыпная плотность, g/l & 60
\end{tabular}

\section{Материалы и методы}

В качестве полимерной матрицы для композитов использовались ПММА марки Дакрил-61 и ПС марки 585. Наполнителем служили наночастицы диоксида кремния $\left(\mathrm{SiO}_{2}\right)$, модифицированные силазанами Aerosil R812 (Evonic Industries, Германия). Концентрации наполнителя рассчитывались по массе полимера и составляли
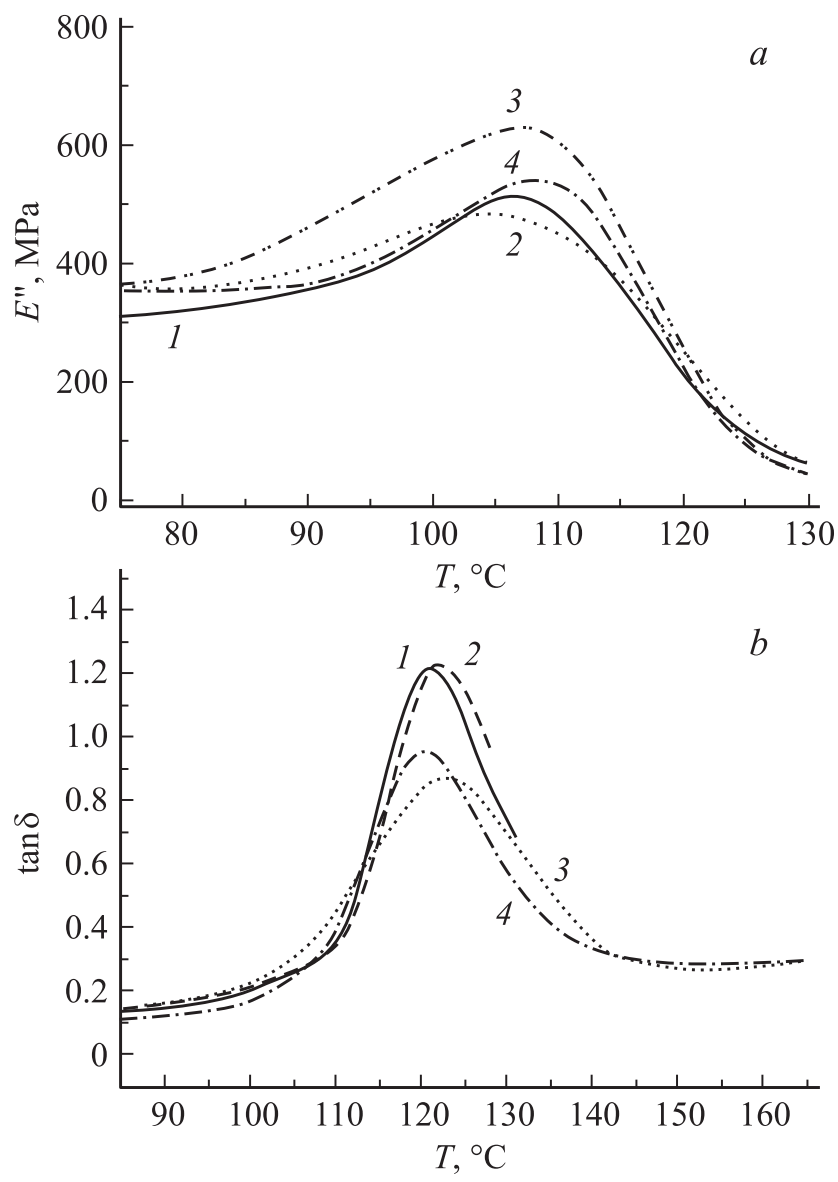

Рис. 1. Температурная зависимость модуля потерь (a) и тангенса угла механических потерь $(b)$ при испытании на трехточечный изгиб композитов на основе ПММА: 1 - чистый ПММА, 2 - ПММА +5 mass.\% $\mathrm{SiO}_{2}, 3$ ПММА +10 mass. $\% \mathrm{SiO}_{2}, 4-$ ПMМА +20 mass. $\% \mathrm{SiO}_{2}$.
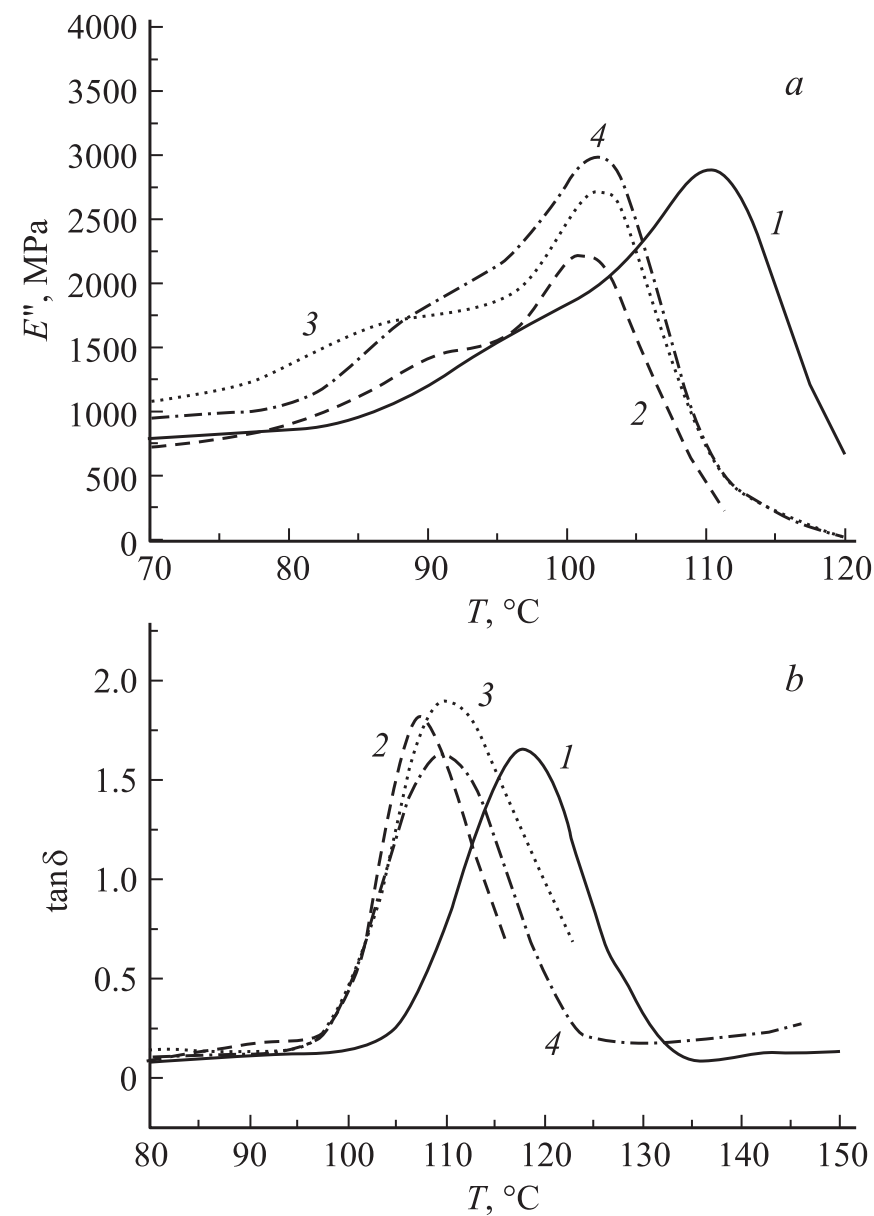

Рис. 2. Температурная зависимость модуля потерь $(a)$ и тангенса угла механических потерь $(b)$ при испытании на трехточечный изгиб композитов на основе ПС: 1 - чистый ПС, $2-\Pi$ С +5 mass. $\% \mathrm{SiO}_{2}, 3-\Pi \mathrm{C}+10$ mass. $\% \mathrm{SiO}_{2}, 4-$ $\Pi \mathrm{C}+20$ mass. $\% \mathrm{SiO}_{2}$.

$K_{\mathrm{SiO}_{2}}=5,10,20$ mass.\%. В табл. 1 приведены характеристики наночастиц диоксида кремния.

Изготовление блочных образцов ПНК на основе ПММА и ПС производилось по расплавной технологии. Для этого использовался двушнековый микрокомпаундер DSM Xplore $5 \mathrm{ml}$ Microcompounder, производства DSM Xplore (Нидерланды). В случае получения композитов на основе ПММА смешение осуществлялось при температуре $230^{\circ} \mathrm{C}$ в течение $10 \mathrm{~min}$ и скорости вращения шнеков $50 \mathrm{rpm} / \mathrm{min}$. После этого происходило формование блочного образца путем впрыскивания расплава полимера в пресс-форму, нагретую до $180^{\circ} \mathrm{C}$. Затем пресс-форма вынималась из микроинжектора и охлаждалась до комнатной температуры на воздухе. При создании композитов на основе ПС температура смешения в камере экструдера составляла $220^{\circ} \mathrm{C}$, а пресс-формы - $80^{\circ} \mathrm{C}$. Таким образом, были получены блочные образцы композитов с нановключениями $\mathrm{SiO}_{2}$ и образцы из чистых ПММА и ПС без включений. Образцы имели размеры $50 \times 10 \times 1.5 \mathrm{~mm}$. 
$a$
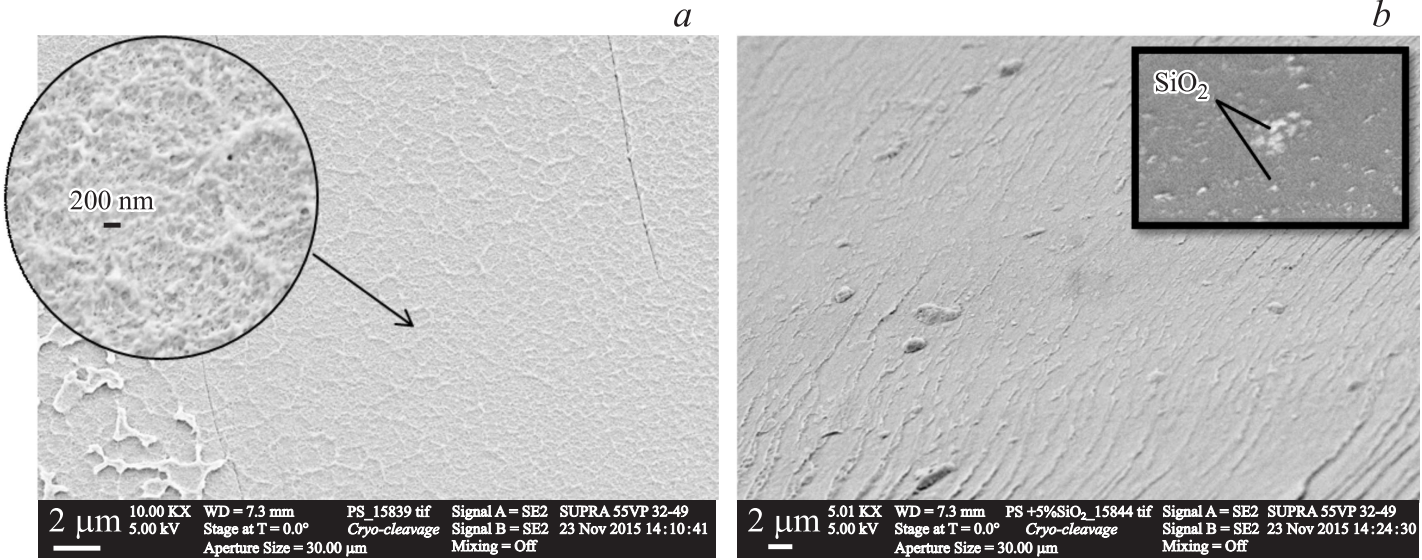

$c$
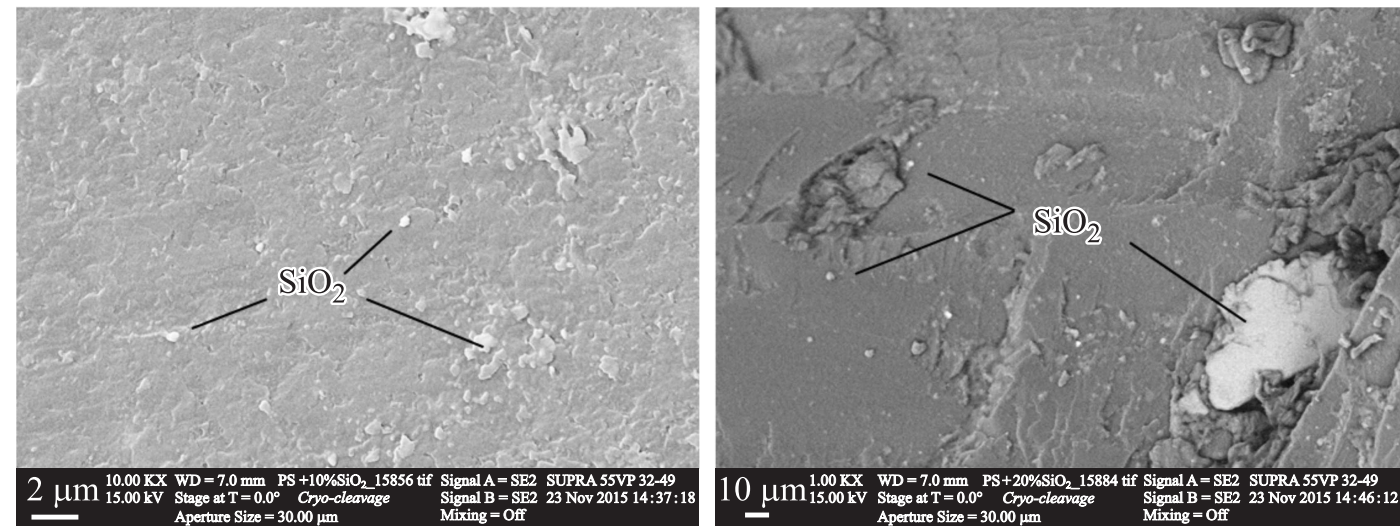

Рис. 3. Микрофотографии поверхности криосколов блочных образцов ПНК: $a-$ чистый ПС, $b-\Pi_{\mathrm{C}}+5 \mathrm{mass}^{\circ} \% \mathrm{SiO}{ }_{2}, c-$ $\Pi \mathrm{C}+10$ mass. $\% \mathrm{SiO}_{2}, d-\Pi \mathrm{C}+20$ mass. $\% \mathrm{SiO}_{2}$.

Влияние концентрации модифицированного силазанами диоксида кремния на вязкоупругие свойства ПНК на основе ПММА и ПС изучалось с помощью динамического механического анализа (ДМА) по методике трехточечного изгиба. Исследования проводились на установке DMA 242C (Netzsch, Германия) в области температур от -50 до $200^{\circ} \mathrm{C}$ при частоте $1 \mathrm{~Hz}$, динамической силе $2 \mathrm{H}$ и скорости нагрева $5 \mathrm{deg} / \mathrm{min}$. Были определены температурные зависимости трех параметров: модулей упругости $\left(E^{\prime}\right)$ и потерь $\left(E^{\prime \prime}\right)$ при изгибе, а также тангенса угла механических потерь $(\operatorname{tg} \delta)$.

Оценка степени диспергирования наночастиц диоксида кремния в объеме полимерных матриц производилась на основе микрофотографий поверхности криосколов ПНК, полученных с использованием сканирующего электронного микроскопа Supra-55 фирмы Carl Zeiss, Германия.

\section{Результаты и их обсуждение}

Результаты исследования вязкоупругих свойств ПНК на основе ПММА и ПС матриц в зависимости от концентрации $\mathrm{SiO}_{2}$ представлены на рис. 1, 2 и в табл. 2. Значения температуры стеклования $T_{g}$ определялись как максимум на графике температурной зависимости модуля потерь при изгибе и тангенса угла механических потерь.

На рис. 1 видно, что введение модифицированных частиц диоксида кремния в ПММА матрицу не оказывает влияния на значение температуры стеклования полимера, т.е. на его теплостойкость. В случае ПС матрицы (рис. 2), введение наполнителя приводит к небольшому смещению $T_{g}$ ПНК в область меньших температур. Можно предположить, что наполнитель в этом случае выступает в роли пластификатора, увеличивая сегментальную подвижность макромолекулярных цепей полимера, причем такое смещение $T_{g}$ не зависит от концентрации наночастиц $\mathrm{SiO}_{2}$.

Таблица 2. Значения модуля упругости при изгибе, измеренного при комнатной температуре для нанокомпозитов на основе ПММА и ПС

\begin{tabular}{c|c|c|c|c}
\hline \multirow{2}{*}{$\begin{array}{c}\text { Матрица } \\
\text { композита }\end{array}$} & \multicolumn{4}{|c}{ Модуль упругости при изгибе, $\mathrm{GPa}$} \\
\cline { 2 - 5 } & $0 \%$ & $5 \% \mathrm{SiO}_{2}$ & $10 \% \mathrm{SiO}_{2}$ & $20 \% \mathrm{SiO}_{2}$ \\
\hline ПММА & 3.69 & 3.92 & 4.11 & 4.89 \\
ПС & 2.42 & 2.93 & 2.97 & 3.12
\end{tabular}




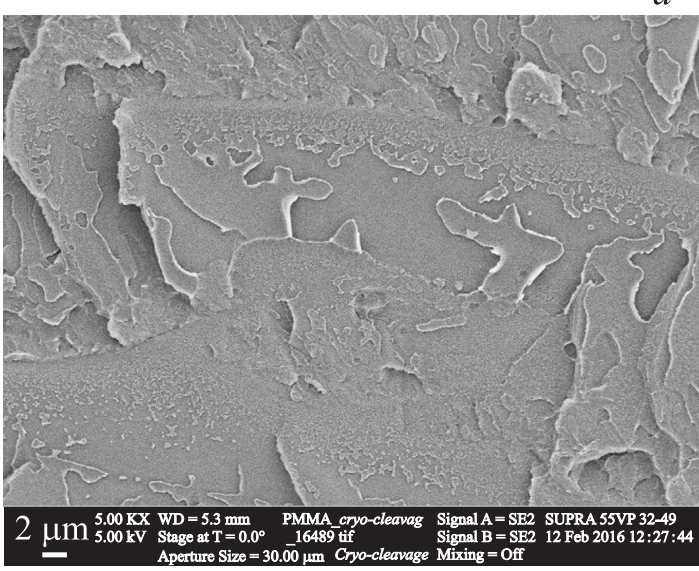

$b$

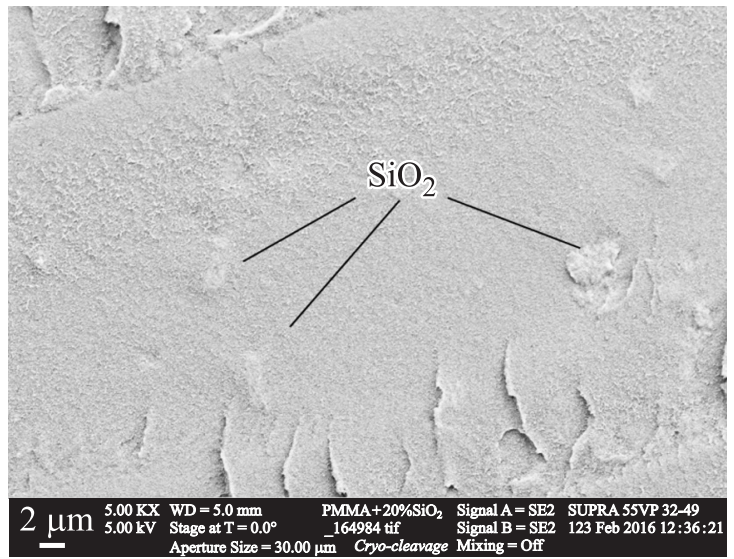

Рис. 4. Микрофотографии поверхности криосколов блочных образцов ПНК на основе: $a-$ чистого ПММА и $b-$ ПММА наполненного 20 mass.\% $\mathrm{SiO}_{2}$.

Анализируя данные табл. 2, можно сделать общий вывод о плавном повышении модуля упругости при изгибе с увеличением концентрации наночастиц $\mathrm{SiO}_{2}$. Так, при содержании диоксида кремния, равном 20 mass.\%, модуль упругости $E^{\prime}$ повышается в среднем на $30 \%$ независимо от типа полимерной матрицы. Такой эффект согласуется с результатами, полученными другими исследователями $[14,15]$. Стоит отметить, что введение дисперсных частиц в термопластичные матрицы методом in situ позволяет добиться похожих результатов, но при меньших концентрациях наполнителя $[10,11]$. Такое различие может объясняться не достаточно равномерным диспергированием наноразмерных частиц в объеме полимерной матрицы. Поэтому далее исследовался характер распределения частиц $\mathrm{SiO}_{2}$ в ПНК, полученных на основе ПС и ПММА.

Электронные микрофотографии поперечных криосколов, полученных ПНК на основе ПС матрицы, представлены на рис. 3, $a$ на основе ПММА матрицы на рис. 4. Как видно из микрофотографий (рис. 3), при концентрации наполнителя 5 mass.\% он достаточно равномерно диспергируется в объеме ПС матрицы, однако местами наблюдаются агломераты эллипсообразной формы со средним размером до $2 \mu \mathrm{m}$ (рис. $3, b$ ). Введение бо́льших концентраций дисперсных частиц приводит к увеличению размеров агрегатов (рис. $3, c, d$ ). Так, при концентрации 20 mass.\% $\mathrm{SiO}_{2}$ (рис. $3, d$ ) их размер может достигать $40 \mu \mathrm{m}$.

Аналогичная картина наблюдается и при исследовании поперечных криосколов ПНК, полученных на основе ПММА (рис. 4). С повышением содержания дисперсного наполнителя в объеме полимерной матрицы он начинает агрегировать и при концентрации 20 mass.\% размеры агломератов достигают $5 \mu \mathrm{m}$ (рис. $4, b)$.

Поэтому представляется целесообразным в дальнейшем для получения по расплавной технологии оптически прозрачных образцов ПНК с контролируемыми упругими характеристиками исследовать также возможность увеличения степени диспергирования нанонаполнителя в объеме полимера. Полученные образцы используются нами для исследования распространения объемных нелинейных волн (солитонов) деформации с целью их практического применения в дефектоскопии и неразрушающем контроле конструкционных элементов, выполненных из этих материалов, а также при разработке принципиально новых методов определения модулей упругости третьего порядка [16].

\section{Заключение}

Таким образом, в настоящей работе методом расплавной технологии были получены ПНК на основе ПММА и ПС матриц, содержащие в качестве наполнителя модифицированные силазаном наночастицы $\mathrm{SiO}_{2}$. Из этих композитов были спрессованы блочные образцы с различными концентрациями $\mathrm{SiO}_{2}$ и исследованы их вязкоупругие свойства методом ДМА. Показано, что введение 20 mass.\% $\mathrm{SiO}_{2}$ приводит к увеличению на 30\% модуля упругости полимерных матриц при изгибе. При этом в случае ПС матрицы дисперсные частицы также оказывают влияние на температуру стеклования ПНК, определенную по методу ДМА (максимумы модуля потерь или тангенса угла механических потерь). Полученные результаты позволят в дальнейшем применить синтезированные нанокомпозиты для исследования распространения объемных нелинейных волн (солитонов) деформации с целью разработки методик неразрушающего контроля и дефектоскопии функциональных и конструкционных элементов, выполненных из армированных ПНК.

Исследование было поддержано грантом Российского научного фонда № 14-12-00342. 


\section{Список литературы}

[1] Samsonov A.M. Strain Solitons in Solids and how to construct them. London, NY: Chapman \& Hall/CRC Press, Boca Raton, 2001. 248 p.

[2] Samsonov A.M., Dreiden G.V., Semenova I.V.// Proc. IMechE. 2008. Vol. 222. N 10. P. 1975-1980.

[3] Дрейден Г.В., Самсонов А.М., Семенова И.В. // ЖТФ. 2008. Т. 78. Вып. 5. С. 8-14.

[4] Jeon I.-Y., Baek J.-B. // Materials. 2010. Vol. 3. P. 3654-3674.

[5] Suprakas S.R., Masami O. // Prog. Polym. Sci. 2003. Vol. 28. P. 1539-1641.

[6] Thostenson E.T., Li C., Chou T.-W. // Composit. Sci. Technol. 2005. Vol. 65. N 3-4. P. 491-516.

[7] Hanemann T., Szabó D.V. // Materials. 2010. Vol. 3. P. 3468-3517.

[8] Carotenuto G., Nicolais L., Kuang X., Zhu Z. // Appl. Comp. Mater. 1995. Vol. 2. P. 385-393.

[9] Yunhua Y., Yi.D. // Colloid. Polym. Sci. 2003. Vol. 281. P. 794-799.

[10] Stojanovic D., Orlovic A., Markovic S., Radmilovic V., Uskokovic P.S., Aleksic R. // J. Mater. Sci. 2009. Vol. 44. P. 6223-6232.

[11] Etienn S., Becker C., Ruch D., Grignard B., Cartigny G., Detrembleur C., Calberg C., Jerome R. // J. Thermal Analys. Calorimetr. 2007. Vol. 87. N 1. P. 101-104.

[12] $W u$ W., Wagner M.H., Xu Z. // Colloid. Polym. Sci. 2003. Vol. 281. P. 550-555.

[13] Tang E., Cheng G., Ma X. // Powder Technology. 2006. Vol. 161. N 3. P. 209-214.

[14] Santos Silva E., Ribeiro L.A. // Mater. Research. 2014. Vol. 17. N 4. P. 926-932.

[15] Lach R., Kim G.-M., Michler G.H., Grellmann W., Albrecht K. // Macromol. Mater. Eng. 2006. Vol. 291. P. 263271.

[16] Гарбузов Ф.Е., Самсонов А.М., Семенов А.А., Швари А.Г. // Письма в ЖТФ. 2016. Т. 42. Вып. 3. С 16-22. 